\title{
Quantitative Analysis of Barakol Content in Senna siamea Leaves and Flowers by TLC-Densitometry
}

\author{
Tanit Padumanonda ${ }^{a}$ Leena Suntornsuk ${ }^{b}$ Wandee Gritsanapan ${ }^{a}$ \\ Departments of a Pharmacognosy and ${ }^{b}$ Pharmaceutical Chemistry, Faculty of Pharmacy, Mahidol University, \\ Bangkok, Thailand
}

\section{Key Words}

Thin-layer chromatography-densitometry • Barakol •

Senna siamea

\begin{abstract}
Objective: To develop a TLC-densitometric method for the determination of barakol content in Senna siamea leaf and flower extracts, and to compare the barakol content in mature leaves, young leaves and young flowers of the plant which are consumed as a vegetable in curry. Materials and Methods: The extraction of pure barakol was performed by boiling the fresh young leaves of $S$. siamea with $0.5 \%$ sulfuric acid followed by chloroform extraction. The extract was further purified and recrystallized from absolute ethanol. Authentic sample of barakol was used for the validation of the TLC-densitometric method. Chromatography was performed on a TLC aluminium plate precoated with silica gel $60 \mathrm{~F}_{254}$ as a stationary phase and chloroform-methanol (85:15 v/v) as a solvent system. Fifteen percent ethanolic extracts of mature leaves, young leaves and flowers of S. siamea were analyzed and compared for barakol content using the validated TLC-densitometric method. Both the validation and analysis of barakol by TLC-densitometry were carried out at the absorbance mode of $366 \mathrm{~nm}$. Results: Barakol was extracted as pure lemon-yellow crystals from young $S$. siamea leaves with $0.1 \%$ yield. Linearity was found over the range of $200-900 \mathrm{ng} / \mathrm{spot}\left(\mathrm{r}^{2}=0.997\right)$. The developed meth-
\end{abstract}

od gave high precision (\%RSD < 0.50) and accuracy (average $101.12 \%)$. The limit of detection and limit of quantitation were 8 and $50 \mathrm{ng}$, respectively. Barakol content in young leaves, mature leaves and young flowers were 1.67, 0.78 and $1.43 \%$ dry weight, respectively. $R_{f}$ value of the barakol in young leaves, young flowers and authentic sample was the same: $0.45 \pm$ 0.03. Conclusion: The TLC-densitometric method was simple, precise and convenient; hence it is an effective procedure for the simultaneous determination of barakol in plant extracts.

Copyright $\odot 2007$ S. Karger AG, Basel

\section{Introduction}

Senna siamea (Lam.) Irwin and Barneby is indigenously found in Thailand and locally called 'Khi-Lek'. It has a long history of use as a folk medicine and its therapeutic efficacy is well recognized. Different parts of $S$. siamea can be used for various medical purposes [1-3]. Fresh young leaves and fresh young flowers of S. siamea have been used as vegetable in Thailand by boiling in water for half an hour, and then the boiled water is discarded. The marc is reboiled for another 1-2 times as before and the boiled leaves are then mixed with coconut milk and curry paste and cooked as a curry. Khi-lek curry is a well-known dish of Thailand and recommended to consume as a health food for a mild laxative and sleeping aid. 


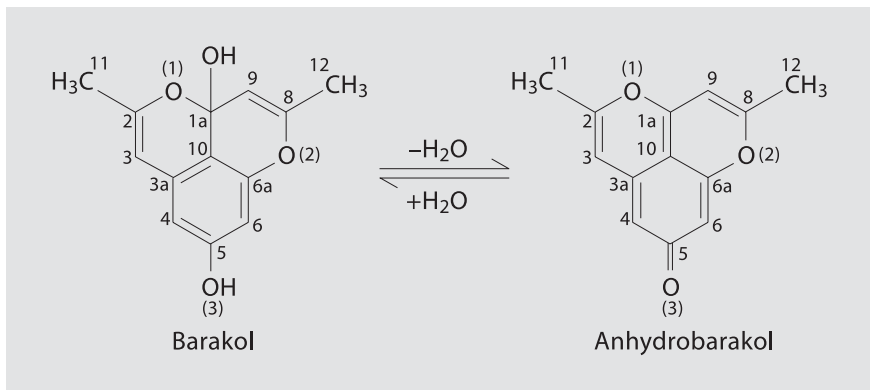

Fig. 1. The conversion reaction of barakol and anhydrobarakol.

An aqueous extract of fresh or dried leaves of $S$. siamea has also been recommended for treatment of insomnia [4]. For the past few decades, barakol, a major and biologically active constituent of the extract of $S$. siamea, especially from young leaves, has been extensively studied for its anxiolytic activity [5-7].

Barakol (3,4-dihydroxy-2,5-dimethyl-1,4-dioxyphenalene, $\mathrm{C}_{13} \mathrm{H}_{12} \mathrm{O}_{4}$, melting point $166-170^{\circ} \mathrm{C}$ : decomposed) contains a tricyclic ring structure [8]. It is converted to anhydrobarakol $\left(\mathrm{C}_{13} \mathrm{H}_{10} \mathrm{O}_{3}\right.$, melting point $\left.163^{\circ} \mathrm{C}\right)$ by losing a molecule of water (fig 1). Barakol occurs as pale lemon-yellow needle crystals.

There are few methods for the quantitation of barakol in plant extracts. Siripunya [9] reported an HPLC method for the determination of barakol in alcoholic solution and in syrup formulation containing S. siamea extract. Thongsaard et al. [10] reported the application of an HPLC method with electrochemical detection to determine the extent of purity and stability of extracted barakol solution. So far, there is no report related to thin-layer chromatography (TLC)-densitometry for the determination of barakol in the extracts from different parts of S. siamea. Thus, the aim of this study was to develop and validate a TLC-densitometric method for the determination of barakol in S. siamea extracts and to compare barakol content in mature leaves, young leaves and young flowers of the plant, which are consumed as a vegetable in curry.

\section{Materials and Methods}

Plant Materials and Reagents

Samples of mature leaves, young leaves and flowers of S. siamea were collected from the Bangkok area, Thailand in June 2003 and were identified by comparing them with herbariums (BKF No. 65023, BKF No. 086142) at the Forest Herbarium, Department of National Park, Wildlife and Plant Conservation, Ministry of Natural Resources and Environment, Bangkok, Thailand. The voucher specimens were kept at the Department of Pharmacognosy, Faculty of Pharmacy, Mahidol University, Bangkok, Thailand. The samples were dried in a hot air oven at $60^{\circ} \mathrm{C}$ and the dried samples were ground by an electronic hammer mill to produce powders. All reagents and solvents used for analysis were of analytical grade. Barakol was extracted and purified by the method modified from Thongsaard et al. [5].

\section{Extraction and Purification of Barakol for Using as a \\ Standard}

Fresh young leaves of $S$. siamea $(6.0 \mathrm{~kg})$ were sliced into small pieces and boiled with 12 liters of $0.5 \%$ sulfuric acid for $15 \mathrm{~min}$; the mixture was then cooled and filtered. The marc was reboiled with $0.5 \%$ sulfuric acid using the same process as before. The filtrates were combined and made basic with an adequate amount of sodium carbonate to $\mathrm{pH}$ 8. The basic solution was extracted with chloroform $(3 \times 4$ liters $)$. The chloroform extracts were combined and shaken twice with deionized water. It was then filtered and concentrated under reduced pressure until the volume was one fourth of the starting volume. An equal amount of deionized water was added and the mixture was cooled for $30 \mathrm{~min}$ to get crude barakol, which was recrystallized from absolute ethanol to get green yellow crystal of barakol. Purified barakol was identified by comparing its UV, IR, $\mathrm{H}^{1}$-NMR spectra and melting point with those of the authentic sample supplied by Dr. Chaichantipyuth C., Chulalongkorn University, Thailand.

\section{Preparation of Standard Solutions}

A stock solution of barakol was prepared by dissolving $10 \mathrm{mg}$ of standard barakol in $10 \mathrm{ml}$ of methanol in a volumetric flask. A standard solution of $100 \mathrm{ppm}$ barakol was prepared by diluting the standard barakol with methanol.

\section{TLC-Densitometry Instrumentation}

A Camag TLC system (Switzerland) composed of an automatic TLC sampler (Linomat IV, Switzerland), TLC scanner and CATS 4 software was used for sample application and quantitative evaluation.

Chromatography was performed on a TLC precoated silica gel $60 \mathrm{~F}_{254}$ plate $20 \times 10 \mathrm{~cm}$ using chloroform-methanol (85:15) as a mobile phase. Total volume of solvent mixture was $30 \mathrm{ml}$. Sample bands were applied (6 mm length) at $9.4 \mathrm{~mm}$ intervals under nitrogen stream. A constant application rate of $0.1 \mu \mathrm{l} / \mathrm{s}$ was employed. The slit dimension was kept at $6 \mathrm{~mm} \times 0.45 \mathrm{~mm}$ and the scanning speed was $10 \mathrm{~mm} / \mathrm{s}$. Plates were developed in the Camag TLC chamber and equilibrated with the mobile phase for $40 \mathrm{~min}$ before inserting the plate. Chromatograms were evaluated using the peak area after scanning in absorbance mode at $366 \mathrm{~nm}$ for barakol.

After development, the plate was dried in air for $5 \mathrm{~min}$, after which sample and standard zones were quantified by linear scanning at $366 \mathrm{~nm}$ by the use of a Camag TLC scanner III with a deuterium source and tungsten source. The WINCATS software controlling the densitometer produced a calibration plot by linear regression analysis relating standard zone weights to their scan areas, and the content of barakol in samples was automatically interpolated from the calibration curve.

In addition to these components, a Camag video documentation system in conjunction with the Reprostar 3 was used for imaging and archiving the TLC. 
Fig. 2. UV spectra of standard barakol overlayed with barakol in the extracts (maximum absorption at 247 and $375 \mathrm{~nm})$.

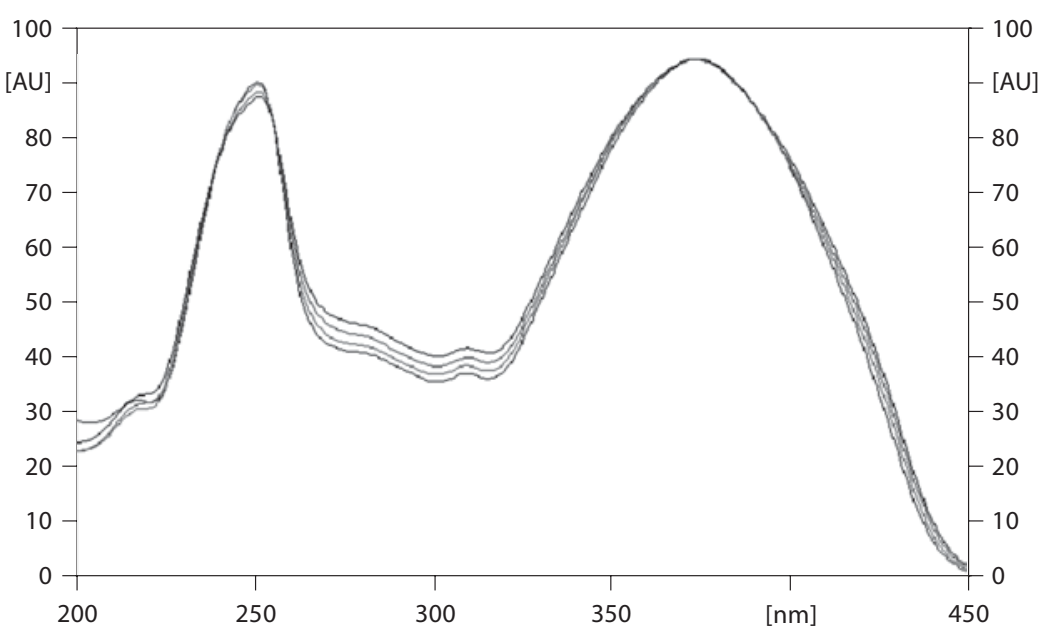

100

80

70

60

10

0

\section{Method Validation}

The HPTLC method was validated in terms of linearity, accuracy, precision, limit of detection (LOD) and limit of quantitation (LOQ). Linearity was determined over the range of 100-1,000 ng. Different volumes of stock solution of barakol (100 ppm), 1-10 $\mu \mathrm{l}$, were spotted on the TLC plate to obtain amounts of 100-1,000 ng of barakol. TLC plates were developed and analyzed as described previously. The data of peak area versus barakol concentration was plotted by linear regression analysis. Accuracy was performed by recovery studies, which were carried out by the standard addition method. The preanalyzed sample was the $15 \%$ alcoholic extract of young leaf powders of S. siamea. The sample solutions were spiked with 50, 75 and $100 \%$ of standard barakol and the mixtures were reanalyzed by the TLC-densitometric method. At each level of the concentration, five determinations were performed. Intraday precision was performed by analyzing barakol at three different concentrations $(300,400$, $500 \mathrm{ng} / \mathrm{spot})$ on the same day $(\mathrm{n}=5)$. Interday precision was carried out in the same manner as intraday precision but on 6 different days $(n=6)$. In order to obtain an estimate of the LOD/LOQ, a series of concentrations of the barakol (range 1-100 ng) were spotted on the TLC plate and analyzed to determine LOD and LOQ by considering the signal-to-noise $(\mathrm{S} / \mathrm{N})$ ratio. LOD was considered as $\mathrm{S} / \mathrm{N}=3: 1$, while $\mathrm{LOQ}$ was $\mathrm{S} / \mathrm{N}=10: 1$.

\section{Preparation of Samples for Estimation and Comparison of} Barakol Content

An accurately weighed $0.1 \mathrm{~g}$ of powder of the mature leaves, young leaves and young flowers of S. siamea (from the same source) was separately extracted with $10 \mathrm{ml}$ of $15 \%$ ethanol. Each sample was sonicated for $1 \mathrm{~h}$ and centrifuged at 3,500 rpm for $10 \mathrm{~min}$ and then filtered. The filtrate was adjusted to the original volume in a volumetric flask with $15 \%$ ethanol. The solution was analyzed for barakol content by applying $3 \mu \mathrm{l}$ of the solution on the TLC plate, followed by developing and scanning as described previously. The concentration of barakol $(\mathrm{mg} / \mathrm{ml})$ in each sample was then calculated and the barakol content (\% dry weight) was then determined.

\section{Results}

\section{Identification of Extracted Barakol}

The detailed characteristics of the extracted barakol including melting point, UV spectrography, details of absorption peaks and NMR chemical shifts are given in table 1. Ultraviolet spectra of the isolated barakol at the start, middle and end positions of the band completely overlapped with the band of the standard barakol (fig. 2). The amounts of barakol in young leaves, mature leaves and young flowers were found to be $1.67,0.78$, and $1.43 \%$ of dried powder, respectively. The purity of the isolated barakol was established as a single band from the TLCdensitometric method (fig. 3). The chromatograms of authentic barakol, mature leaves, young leaves and young flower extracts with an approximate range of $R_{f}$ value $0.42-0.48$ are given in figure 4 . The band of barakol was confirmed by comparing the UV spectrum of a standard band with the corresponding sample band on the Camag TLC scanner.

The linearity for the response of barakol was assessed in a range of 200-900 ng per spot of standard barakol. The calibration lines were represented by linear equation: $y=17.022 x+7352.6\left(r^{2}=0.997\right)$. Accuracy was determined by percentage recovery. The estimation of barakol 
Table 1. Method of identification and characteristics of barakol

\begin{tabular}{|c|c|c|}
\hline \multicolumn{2}{|c|}{ Method } & \multirow{2}{*}{$\begin{array}{l}\text { Characteristic } \\
167^{\circ} \mathrm{C}(\text { decomposed })\end{array}$} \\
\hline 1 & Melting point & \\
\hline 2 & Molecular weight & 232 \\
\hline 3 & Solubility & $\begin{array}{l}\text { soluble in methanol, ethanol and acetone } \\
\text { moderately soluble in chloroform and dichloromethane } \\
\text { readily soluble in benzene, carbon tetrachloride and water }\end{array}$ \\
\hline 4 & $\mathrm{R}_{\mathrm{f}}$ value & $\begin{array}{l}0.45 \pm 0.03 \\
\text { (silica } \mathrm{GF}_{254}, \text { chloroform:methanol 85:15) }\end{array}$ \\
\hline 5 & Color & pale yellow \\
\hline 6 & UV & $\lambda \max (\mathrm{MeOH})$ at 247 and $375 \mathrm{~nm}$ \\
\hline 7 & IR & $\begin{array}{l}-3,453.7 \mathrm{~cm}^{-1} \text { and } 3,295.8 \mathrm{~cm}^{-1} \text { (broad) } \\
{[\text { characteristic peak of hydroxyl group }(-\mathrm{OH})]} \\
-1,683.4 \mathrm{~cm}^{-1} \text { (sharp) } \\
{[\text { characteristic peak of carboxyl group }(\mathrm{C}=\mathrm{O})]} \\
-1,591.2 \mathrm{~cm}^{-1} \text { and } 1,564.9 \mathrm{~cm}^{-1} \text { (sharp) } \\
{[\text { characteristic peak of aromatic rings] }} \\
-1,472.8 \mathrm{~cm}^{-1} \text { (sharp) } \\
\text { [characteristic peak of C-H stretching] }\end{array}$ \\
\hline \multirow[t]{8}{*}{8} & ${ }^{1} \mathrm{H}-\mathrm{NMR}$ & \\
\hline & $\begin{array}{l}\text { Position (numbering } \\
\text { as in fig. 1) }\end{array}$ & chemical shift (ppm) \\
\hline & 3 & $6.34(1 \mathrm{H}, s)$ \\
\hline & 4 & $6.46\left(1 \mathrm{H}, d, J_{\text {meta }}\right)$ \\
\hline & 6 & $6.57\left(1 \mathrm{H}, d, J_{\text {meta }}\right)$ \\
\hline & 9 & $6.10(1 \mathrm{H}, s)$ \\
\hline & $2-\mathrm{Me}$ & $2.25(3 \mathrm{H}, s)$ \\
\hline & $8-\mathrm{Me}$ & $2.42(1 \mathrm{H}, s)$ \\
\hline
\end{tabular}

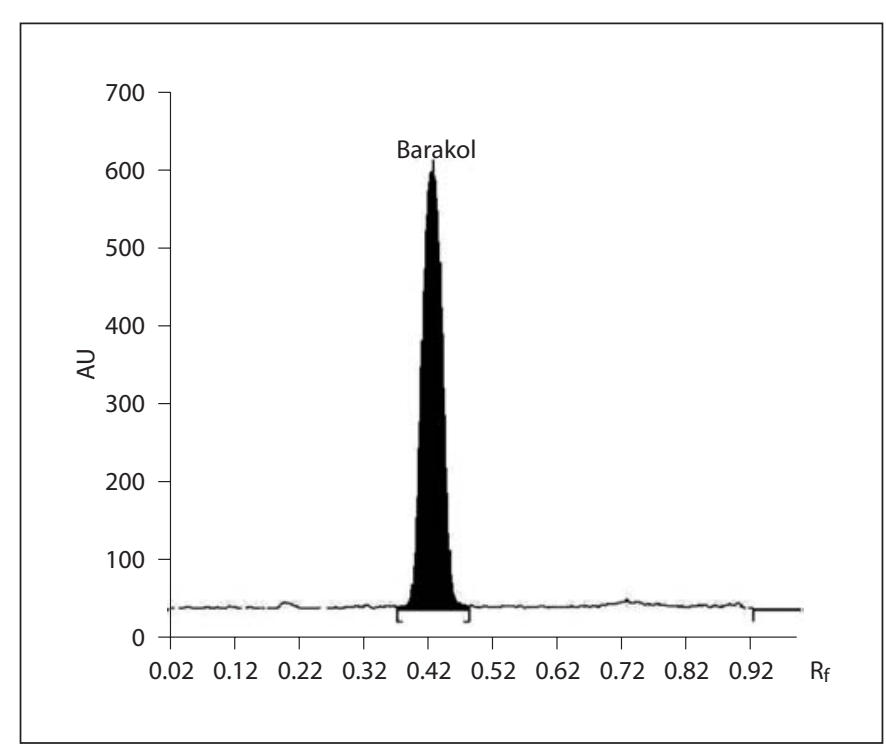

Fig. 3. Single chromatographic band of isolated barakol indicating its purity. in the ethanolic solution after spiking with 50, 75 and $100 \%$ of additional standard barakol afforded recoveries of $101.53,99.80$, and $101.78 \%$, respectively, as shown in table 2 . Average accuracy was $101.12 \%$. The relative standard deviation precision for intra- and interday analysis ranged from 0.18 to $0.26 \%$ and from 0.25 to $0.49 \%$. The LOD with $\mathrm{S} / \mathrm{N}$ ratio of $3: 1$ was found to be $8 \mathrm{ng} / \mathrm{spot}$. The LOQ ratio of 10:1 was found to be $50 \mathrm{ng} / \mathrm{spot}$.

\section{Discussion}

The TLC-densitometric method was fast, convenient and required small amounts of solvent and sample. The $15 \%$ ethanol was exhaustively used in extracting barakol from young leaves, young flowers and mature leaves of $S$. siamea as had successfully been applied to the analysis of pharmaceutical formulations of zolpidem hemitartrate and melatonin $[11,12]$, and to analysis of natural com- 
Fig. 4. Comparison of chromatograms of standard barakol and scan area with barakol content in mature leaf, young leaf and young flower extracts ( $15 \%$ ethanol) of S. siamea. Chromatograms of standard barakol $\left(\mathrm{R}_{\mathrm{f}}=0.44\right.$, scan area: $10,974.55-$ $15,010.32, n=5, a)$, barakol of mature leaf extracts $\left(R_{f}=0.44\right.$, average scan area: $11,458.11, n=5, \mathbf{b})$, barakol of young leaf extracts $\left(\mathrm{R}_{\mathrm{f}}=0.44\right.$, average scan area: $16,211.43, n=5, c)$, barakol of young flower extracts $\left(R_{f}=0.44\right.$, average scan area: $14,992.04, \mathrm{n}=5, \mathrm{~d})$.

Table 2. Accuracy of barakol by TLC-densitometric method $(\mathrm{n}=5)$

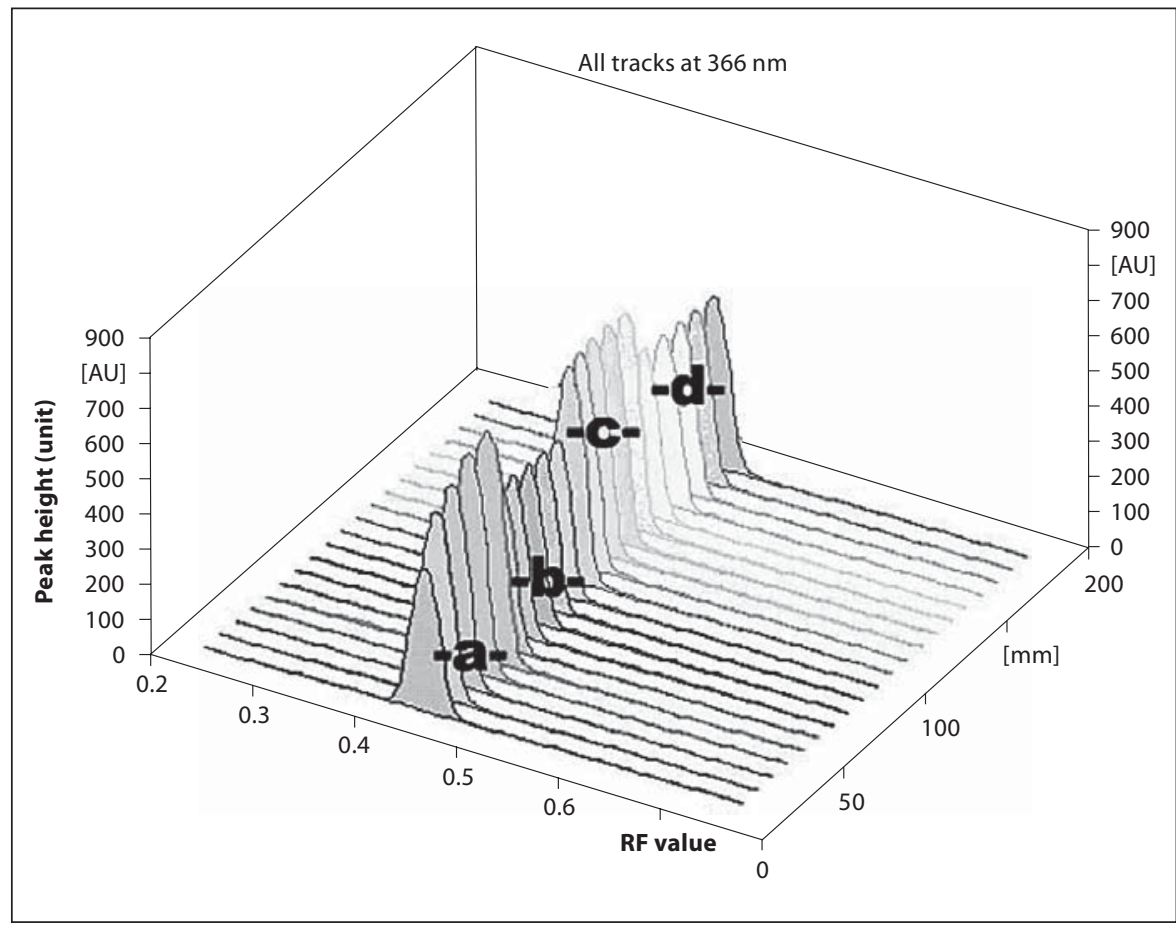

\begin{tabular}{lllrlr}
\hline $\begin{array}{l}\text { Excess barakol added } \\
\text { to the matrix, \% }\end{array}$ & $\begin{array}{l}\text { Theoretical } \\
\text { content, ng/spot }\end{array}$ & $\begin{array}{l}\text { Experimental } \\
\text { content, ng/spot }\end{array}$ & $\begin{array}{l}\text { Accuracy } \\
\%\end{array}$ & $\begin{array}{l}\text { RSD } \\
\%\end{array}$ & $\begin{array}{l}\text { DEV } \\
\%\end{array}$ \\
\hline 50 & 620.76 & 630.29 & 101.53 & 1.99 & 1.53 \\
75 & 720.76 & 719.35 & 99.80 & 1.03 & 0.19 \\
100 & 820.76 & 835.34 & $\begin{array}{c}101.78 \\
(101.12)^{\mathrm{a}}\end{array}$ & 2.02 & 0.12 \\
& & & \\
\hline
\end{tabular}

$\mathrm{RSD}=$ Relative standard deviation; DEV = deviation from the theoretical value.

a Average accuracy. pounds such as diospyrin and ginsenosides in plant extracts $[13,14]$. Equally important, with a single plate $(20$ $\times 10 \mathrm{~cm}$ ), TLC-densitometry can be used to develop up to 24 chromatographic runs and therefore, several samples can be compared simultaneously as was done in this study. The $\mathrm{R}_{\mathrm{f}}$ value, UV, IR and ${ }^{1} \mathrm{H}-\mathrm{NMR}$ spectral data, and melting point of the purified barakol were similar to those of the authentic sample and also previously reported values [15-17]. Compared to HPLC-ECD, which had been used to determine the purity of pure barakol [10], TLC-dosimetric method is less expensive and therefore offers an alternative method for quantitative analysis of barakol content in S. siamea leaves and flowers.

\section{Conclusion}

The TLC-densitometric method was simple, precise, convenient, and hence it was an effective procedure for the determination of barakol in plant extracts. This technique may also be used for the estimation of barakol in other alcoholic plant extracts.

\section{Acknowledgment}

The authors would like to thank Associate Prof. Dr. Chaiyo Chaichantipyuth, Faculty of Pharmaceutical Sciences, Chulalongkorn University, Bangkok, Thailand, for his kind supplying of authentic barakol. 


\section{References}

$>1$ Sukma M, Chaichantipyuth C, Murakami Y, Tohda M, Matsumoto K, Watanabe H: CNS inhibitory effects of barakol, a constituent of Cassia siamia Lamk. J Ethnopharmacol 2002;83:87-94.

2 Subhadhirasakul S, Khumfang P: Screening of barakol from Cassia plants and some of its biological activities. Songklanakarin J Sci Technol 2000;22:429-434.

$>3$ Fiorino DF, Treit D, Menard J, Lermer L, Phillips AG: Is barakol anxiolytic? Behav Pharmacol 1998;9:375-378.

4 Thongsaard W, Deachapunya C, Pongsakorn S, Boyd EA, Bennett GW, Marsden CA: Barakol: a potential anxiolytic extracted from Cassia siamea. Pharmacol Biochem Behav 1996;53:753-758.

$>5$ Thongsaard W, Pongsakorn S, Sudsuang R, Bennett GW, Kendall DA, Marsden CA: Barakol, a natural anxiolytic, inhibits striatal dopamine release but not uptake in vitro. Eur J Pharmacol 1997;319:157-164.

6 Muangman V, Charoenboon S, Chanthepthewan W, Phisalpong CA: Clinical trial on a herbal medicine, Khi-Lek (Cassia siamea) syrup and tablet for insomnia. Thai J Phytopharm 2001;7:18-22.
7 Pooviboonsuk P, Tappayuthpijarn P, Hincheeranund T: Hypnotic effect and sleep qualities of modified herbal extract from Cassia siamea. J Psychiatr Assoc Thailand 2000;45:251-258.

8 Thongsaard W: Physiological and pharmacological properties of Cassia siamea and its active constituent, barakol. Thai J Physio Sci 1998;11:1-26.

9 Siripunya P: Formulation of Syrup Containing Cassia siamea Lamk. Extract; Master of Science in Pharmacy thesis, Chulalongkorn University, 1997, pp 35-51.

10 Thongsaard W, Bennett GW, Marsden AC Determination of barakol extracted from Cassia siamea by HPLC with electrochemical detection. J Pharm Biomed Anal 2001;25: 853-859.

11 El Zeany BA, Moustafa AA, Farid NF: Determination of zolpidem hemitartrate by quantitative HPTLC and LC. J Pharm Biomed Anal 2003;33:393-401.
12 Costantini A, Paoli F: Melatonin: Quantitative analysis in pharmaceutical oral dosage forms using thin-layer chromatography (TLC) densitometry. Farmaco 1998;53:443447.

13 Ravishankara MN, Shrivastava N, Jayathirtha MG, Padh H, Rajani M: Sensitive highperformance thin-layer chromatographic method for the estimation of diospyrin, a tumour inhibitory agent from the stem bark of Diospyros montana Roxb. J Chromatogr B 2000;744:257-262.

14 Vanhaelen-Fastré RJ, Faes ML, Vanhaelen $\mathrm{MH}$ : High-performance thin-layer chromatographic determination of six major ginsenosides in Panax ginseng. J Chromatogr A 2000;868:269-276.

15 Bycroft BW, Hassaniali WA, Johnson AW, King TJ: Structure and synthesis of barakol: a novel dioxyphenalene derivative from Cassia siamea. J Chem Soc Section C: Organic 1970;12:1686-1689.

16 Hassanali TJ, Wallwork SC: Barakol, a novel dioxyphenalene derivative from Cassia siamea. J Chem Soc (Chem Commun) 1969;12 678.

17 Teeyapant R, Srikun O: Chemical investigation of anydrobarakol from Cassia siamea. Fitoterapia 1988;69:475-476. 